\title{
Seismic Characterization of Internal Salt Cycles: remarks from the Santos Offshore Basin, Southeast Brazil.
}

\author{
Rodrigo Pontes (Petrobras/UFF); Alexandre Maul (Petrobras/UFF) and Cleverson Guizan (UFF)
}

Copyright 2021, SBGf - Sociedade Brasileira de Geofísica.

This paper was prepared for presentation during the $17^{\text {th }}$ International Congress of the Brazilian Geophysical Society held in Rio de Janeiro, Brazil, $16-19$ August 2021.

Contents of this paper were reviewed by the Technical Committee of the $17^{\text {th }}$ International Congress of the Brazilian Geophysical Society and do not necessarily represent any position of the SBGf, its officers or members. Electronic reproduction or storage of any part of this paper for commercial purposes without the written consent of the Brazilian Geophysical Society is prohibited.

\begin{abstract}
After the discovery of the profitable pre-salt province in the Santos Offshore Basin, the oil \& gas industry was challenged to develop several methodologies to reach the reservoirs, including the difficulties related to drill in a salt section with variable mineral composition and thickness variations from a few meters to more than $3 \mathrm{~km}$. The compositional aspect is a key factor during drilling operations, because of the different mineral behavior. Halite is by far the major salt component, especially in the thicker sections, however, seismic reflections inside the salt section, indicate internal salt stratifications, which might reflect significant geological and/or climatic changes during salt precipitation. Experimental and field observations indicate that it is possible to understand the salt formation through the evaporation process, following salt cycles. These cycles, in a predictable way of precipitation are composed by gypsum, halite, sylvite and tachyhydrite. Burial processes affect gypsum and sylvite, dehydrating them and converting to anhydrite and carnallite, respectively. The last group, which is composed by sylvite, tachyhydrite and carnallite is very sensitive to climatic changes. Small variations in water salinity and/or air humidity can avoid these minerals from precipitating or being preserved. Besides, because their high mobility, it is well documented that they can easily mix with the halite mineral, affecting their intrinsic properties. In this work we explore few remarks regarding the characterization of salt cycles using seismic data after the well control. We identify and map four main cycles inside the salt formation, which are not present in the whole area of our studied portion. The lack of cycle records is mostly associated to the basin tectonism, helping us to understand the difficulties in mapping the mentioned cycles. Our main contribution is the evaluation of the impacts when using the mapped salt cycles to deal with the salt section in the Santos Basin. We use well and seismic data and we demonstrate how this methodology contributes to illumination studies, seismic processing, uncertainty analysis regarding depth positioning, inputs for geomechanical evaluation and security for well drilling activities.
\end{abstract}

